\title{
Comportamento empreendedor: análise à luz da visão baseada em recursos
}

Entrepreneurial behavior: resource-based view analysis

Recebido em 09.08.2015. Aprovado em 30.08.2016

Avaliado pelo sistema double blind review

\author{
Jamir Rauta \\ jamirrauta27@gmail.com \\ Universidade Federal do Rio Grande do Sul (CEPAN - UFRS) Porto Alegre - RS \\ Julie Rossato Fagundes \\ jurfagundes@hotmail.com \\ Universidade do Oeste de Santa Catarina - Joaçaba - SC \\ Leandro José Paetzold \\ IIlpaetzold@gmail.com \\ Universidade do Oeste de Santa Catarina - Joaçaba - SC \\ César Augustus Winck \\ cesar.winck@unoesc.edu.br \\ Universidade do Oeste de Santa Catarina - Joaçaba - SC
}

\begin{abstract}
Resumo
Este trabalho objetiva conhecer o processo de adaptação estratégica de uma Vinícola produtora de vinho biodinâmico. Verificaram-se os eventos ocorridos na empresa, para então, analisar a influência do comportamento empreendedor, do determinismo ambiental e do voluntarismo na adaptação estratégica da organização, aliados aos recursos disponíveis durante o processo. Foi feita uma revisão na literatura sobre as referidas teorias, com ênfase na adaptação Estratégica e na Visão Baseada em Recursos. De natureza qualitativa, descritiva e exploratória, a pesquisa se deu através de um estudo de caso, baseada no trabalho de Pettigrew (1987), sobre métodos de adaptação estratégica, onde são investigados três elementos da mudança: o contexto, o conteúdo e o processo. Concluiu-se que o processo de adaptação estratégica da empresa apresenta características de pró atividade e busca por diferencial competitivo, o que caracteriza 0 empreendedorismo aliado à visão de oportunidades e inovação.
\end{abstract}

Palavras-chaves: Empreendedorismo; Estratégia; Adaptação; Recursos; Competitividade.

\begin{abstract}
This work aims to know the process of strategic adaptation of a Winery producing biodynamic wine. We verified the events in the company, to analyze the influence of entrepreneurial behavior, environmental determinism and voluntarism in the strategic adaptation of the organization, together with the resources available during the process. A review was made in the literature on these theories, with emphasis on Strategic Adaptation and Resource Based View. In a qualitative, descriptive and exploratory way, the research was based on a case study based on the work of Pettigrew (1987) on methods of strategic adaptation, where three elements of change are investigated: context, content and process. It was concluded that the process of strategic adaptation of the company presents characteristics of pro activity and search for
\end{abstract}


competitive differential, which characterizes entrepreneurship combined with the vision of opportunities and innovation.

Keywords: Entrepreneurship; Strategy; Adaptation; Resources; Competitiveness.

\section{Introdução}

O empreendedorismo é instigado no ser humano pelo fato de provir de experiências educacionais, situações familiares e vivências profissionais variadas (HISRICH; PETERS, 2004), e a capacidade de inovar é reconhecida como uma das habilidades de um empreendedor. Silva et. al. (2013) destacam que para empreender é necessário aceitar os riscos inerentes ao novo negócio, buscar oportunidades e apresentar capacidade criativa. Nos estudos de Hisrich e Peters (2004) percebeu-se que a aceitação dos riscos está em praticamente todas as definições recentes do empreendedor, onde se faz necessário, dentro do processo empresarial, assumir esses riscos, sejam financeiros, sociais ou psicológicos.

Nesse sentido, o empreendedor é analisado como um agente reflexivo engajado em uma ação proposital na qual ele desenvolve e descobre a oportunidade. Além de estar atento às oportunidades estáticas, dinamicamente o empreendedor gera novas oportunidades e novos negócios por meio de ações embasadas em interpretações subjetivas, ou seja, constrói negócios, parcialmente, utilizando sua habilidade de influenciar o ambiente socioeconômico em seu favor, podendo ele organizar e reorganizar mecanismos socioeconômicos objetivando transformar situações e recursos para proveito prático, influenciando voluntaria e involuntariamente o contexto (SILVA, et. al. 2013).

Dornelas (2003) destaca que uma organização pode buscar novas ideias a partir de diversos fatores, como a necessidade de crescimento, melhoria da performance financeira, conquista de novos clientes ou necessidade de inovar, mas o que importa é como as organizações, através de seus empreendedores corporativos, utilizam essa ideia, de forma a transformá-la em um produto ou serviço que as faça prosperar.

Para Motta (2001) o grande desafio das empresas está centrado na capacidade de busca de novas tecnologias, novos mercados e novos métodos de gerenciamento, e do redesenho dos processos de negócio e de integração total das cadeias de valor da empresa, clientes e fornecedores. Já Vasconcelos e Cyrino (2000) sustentam que as mudanças nas condições ambientais freqüentemente exigem das empresas uma regeneração da sua base de recursos e competências.

Segundo Neto e Freitas (2012) a necessidade da empresa se adaptar às demandas ambientais, seja respondendo às ameaças, seja criando oportunidades, continua sendo a pedra fundamental nos estudos em estratégia.

A estratégia competitiva é a busca de uma posição competitiva favorável em uma indústria, à arena fundamental onde ocorre a concorrência (PORTER, 1989). A diferenciação em uma organização pode estar relacionada ao seu modelo de inovação, sua capacidade de planejamento, a forma de utilização de seus recursos ou à possibilidade de gerar oportunidades. Hamel e Prahalad (1995) afirmam que a competição pelo futuro é uma competição pela participação nas oportunidades, e não pela participação no mercado.

Segundo Rossetto e Rossetto (2005) a adaptação organizacional refere-se à habilidade dos administradores em reconhecer, interpretar e implementar estratégias, de acordo com as necessidades e mudanças percebidas no seu ambiente, considerando os aspectos relevantes na própria empresa, enquanto Mintzberg e Quinn (2001) consideram a estratégia empresarial como um processo organizacional, de várias maneiras inseparável da estrutura, do comportamento e da cultura da companhia na qual é realizada.

O setor vinícola brasileiro é um exemplo de segmento que enfrenta uma constante busca pela inovação, a fim de obter destaque internacional, já que compete com vinícolas amplamente reconhecidas. O Brasil tem figurado como grande player na produção de uvas e vinhos, além de estar aumentando a área cultivada com videiras (EMBRAPA UVA E VINHO, 2015). 
Considerando a importância do setor vinícola no contexto nacional e sua constante busca pela inovação, este trabalho tem o objetivo de identificar a influência do comportamento empreendedor das gestoras no processo de adaptação estratégica de uma Vinícola localizada no meio Oeste do Estado de Santa Catarina, tomando como base o modelo proposto por Pettigrew (1987) e as influências do determinismo ambiental e do voluntarismo, sob o modelo de Hrebiniak e Joyce (1985) e da perspectiva da Visão Baseada em Recursos.

\section{Revisão de literatura}

Em um contexto de globalização, onde rápidas mudanças ocorrem nos setores econômicos, político e social e existe uma crescente competitividade entre as organizações, a atuação empreendedora dos gestores torna-se um recurso importante na adaptação a essas transformações, refletindo na busca de um desempenho superior.

Porter (1989) relaciona estratégia às ações ofensivas ou defensivas para criar uma posição defensável numa indústria, para enfrentar com sucesso as forças competitivas e assim obter um retorno maior sobre 0 investimento. Segundo Hamel e Prahalad (1995), para reinventar seu setor, um desafiante precisa regenerar suas estratégias centrais. Precisa conceber sua definição de mercado, redesenhar as fronteiras da empresa, redefinir suas proposições de valor e repensar suas premissas fundamentais sobre como competir.

Para Penrose (1959) o limite ao crescimento da empresa não está no mercado, mas nos recursos que possui e, sobretudo, na maneira como são utilizados, dando origem à singularidade das empresas, e fomentando 0 aumento da lucratividade das empresas (WERNERFELT,1984). Além disso, mais do que possuir recursos, a perenidade da organização passa pela clareza de sua estratégia (MILES; SNOW, 1978), de seus objetivos e comportamento, principalmente no tocante aonde quer chegar; qual seu posicionamento e proposta para o mercado; seu produto e seu diferencial. Miles e Snow (1978) ainda argumentam que a empresa é fruto de um propósito articulado e de um mecanismo estabelecido para realizá-lo. Em meio a incertezas e competição global, possuir flexibilidade e inovação, aliadas à capacidade dos gestores de coordenar e redefinir as competências organizacionais são marcas de empresas vencedoras (TEECE; PISANO; SHUEN, 1997).

Ao levar-se o conceito para a área empresarial, Ansoff (1965) alerta para um aspecto da estratégia: a ideia de mapear as futuras direções da organização a partir dos recursos que possui. É nesse sentido, onde os recursos passam a assumir importância significativa no estabelecimento das estratégias e na busca pela vantagem competitiva, que a atuação empreendedora e a Visão Baseada em Recursos (Resource Based View - RBV) ganham relevância.

Em um mercado homogêneo, as estratégias, que antes eram estabelecidas partindo-se das condições ambientais, passaram a ser formuladas a partir de seus recursos (BARNEY, 1991) e o comportamento empreendedor dos gestores garante vantagem competitiva no processo de adaptação da organização.

\section{O processo de adaptação - Modelo de Pettigrew (1987)}

O processo de adaptação estratégica em uma organização faz-se necessário na busca constante pela competitividade e pode ser analisado sob a ótica de diferentes teorias, partindo de pressupostos que avaliam a influência do ambiente sobre tal processo, como a escolha estratégica e o determinismo ambiental.

O ponto de partida para a mudança estratégica é a noção de que a formulação do conteúdo de qualquer nova estratégia, inevitavelmente, implica em gerir seu contexto e processo (PETTIGREW, 1987).

Para Pettigrew (1987) o conteúdo refere-se às transformações em análise, que podem ser classificadas de acordo com as características que induzem à mudança; 0 contexto refere-se aos aspectos sociais, 
econômicos e políticos do ambiente no qual a empresa opera; O processo refere-se às ações, reações e interações entre as partes interessadas, que procuram passar a empresa de seu estado atual para um estado futuro.

Para entender a mudança sob uma visão holística, segundo Pettigrew (1987) é necessário observar sempre a interação entre estes elementos nas transformações da organização, conforme modelo apresentado na Figura 1.

Pettigrew (1987) ainda considera que o processo de mudança nas organizações deve ser analisado sob uma ótica contextualista e processual, e para tal, os líderes devem desenvolver e implantar estratégias a partir das mudanças no contexto (...) através de uma nova postura ideológica que desafia sua forma de pensar e agir, chamando a atenção para as necessidades de novos recursos e habilidades (PETTIGREW, 1987).

Hrebiniak e Joyce (1985) defendem que a posição de uma organização pode mudar ao longo do tempo, como resultado tanto de escolhas estratégicas como de mudanças no ambiente externo. Para Astley e Van de Ven (1983) o questionamento central da adaptação estratégica organizacional é se ela deriva do aspecto gerencial ou ambiental, não podendo ser classificada a partir de uma dicotomia de conceitos.

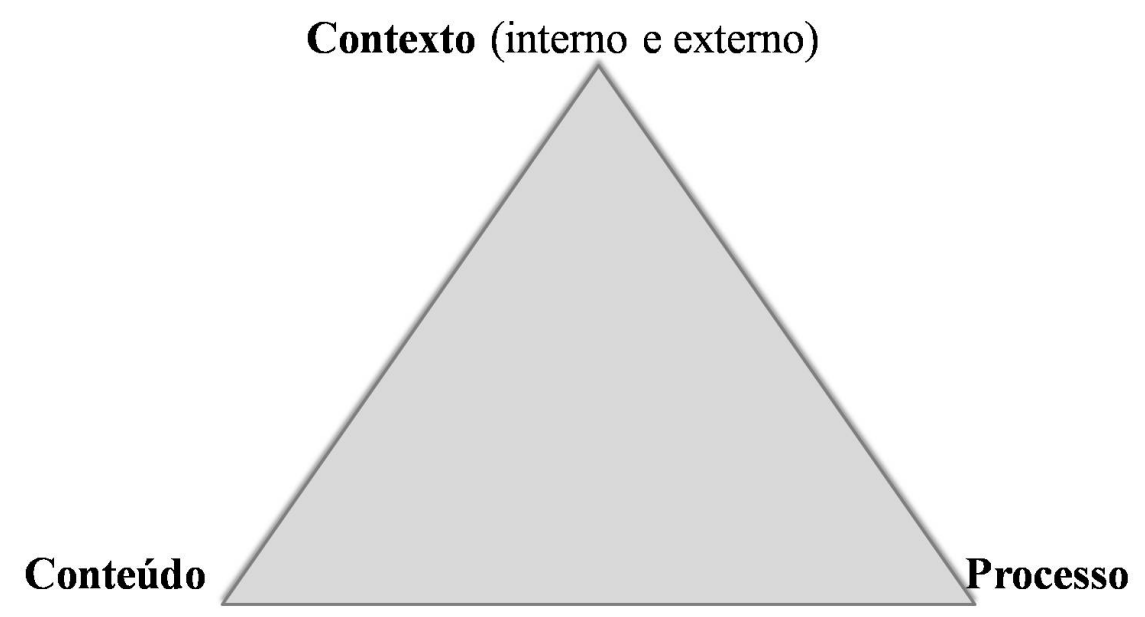

Figura 1. A tríade para o estudo da adaptação estratégica.

Fonte: Adaptado de Pettigrew (1987), pelos Autores (2016).

Segundo Vegini e Fiates (2011) na ação recíproca entre organização e ambiente, as mudanças empreendidas podem ser entendidas de duas formas, dependendo de como 0 ambiente influencia ou não a iniciativa e a escolha das mudanças. Nesse sentido, os estudos sobre adaptação estratégica tem-se dividido entre o processo de escolha e a reação às pressões ambientais. Para Pettigrew (1987), mesmo sob forte pressão ambiental, a organização é capaz de definir suas ações e estratégias, ainda que limitadas pelo contexto.

Na esteira de Astley e Van de Ven (1983), Hrebiniak e Joyce (1985) argumentam que: (1) escolha e determinismo não são fins opostos de um único contínuo de efeito, mas na realidade representam duas variáveis independentes, e (2) a interação ou interdependência dos dois precisa ser estudada para explicar o comportamento organizacional.

\section{O modelo de Hrebiniak e Joyce (1985)}

Buscando desenvolver uma visão interativa do processo de adaptação estratégica nas organizações além da exaustiva revisão teórica de Astley e Van de Ven (1983), Hrebiniak e Joyce (1985) desenvolveram uma tipologia de tomada de decisão estratégica que facilita o estudo das interações entre determinismo e voluntarismo, já que, segundo Carvalho et. al. (2011) isoladamente, nenhuma das abordagens teóricas 
discutidas por Astley e Van de Ven (1983) poderia explicar todo o processo de adaptação estratégica de uma organização.

Para Hrebiniak e Joyce (1985) escolha estratégica e determinismo ambiental podem ser representados em eixos, variando de baixo a alto, conforme demonstrado na Figura 2, a partir de diferentes comportamentos: (I) seleção natural, com mínima capacidade de escolha, (II) diferenciação com alta capacidade de escolha estratégica e de determinismo ambiental, (III) escolha estratégica com máxima capacidade de escolha, (IV) escolha indiferente, com adaptação casual. Segundo os autores, sob essa perspectiva, as organizações adaptam-se ou são eliminadas por seleção.

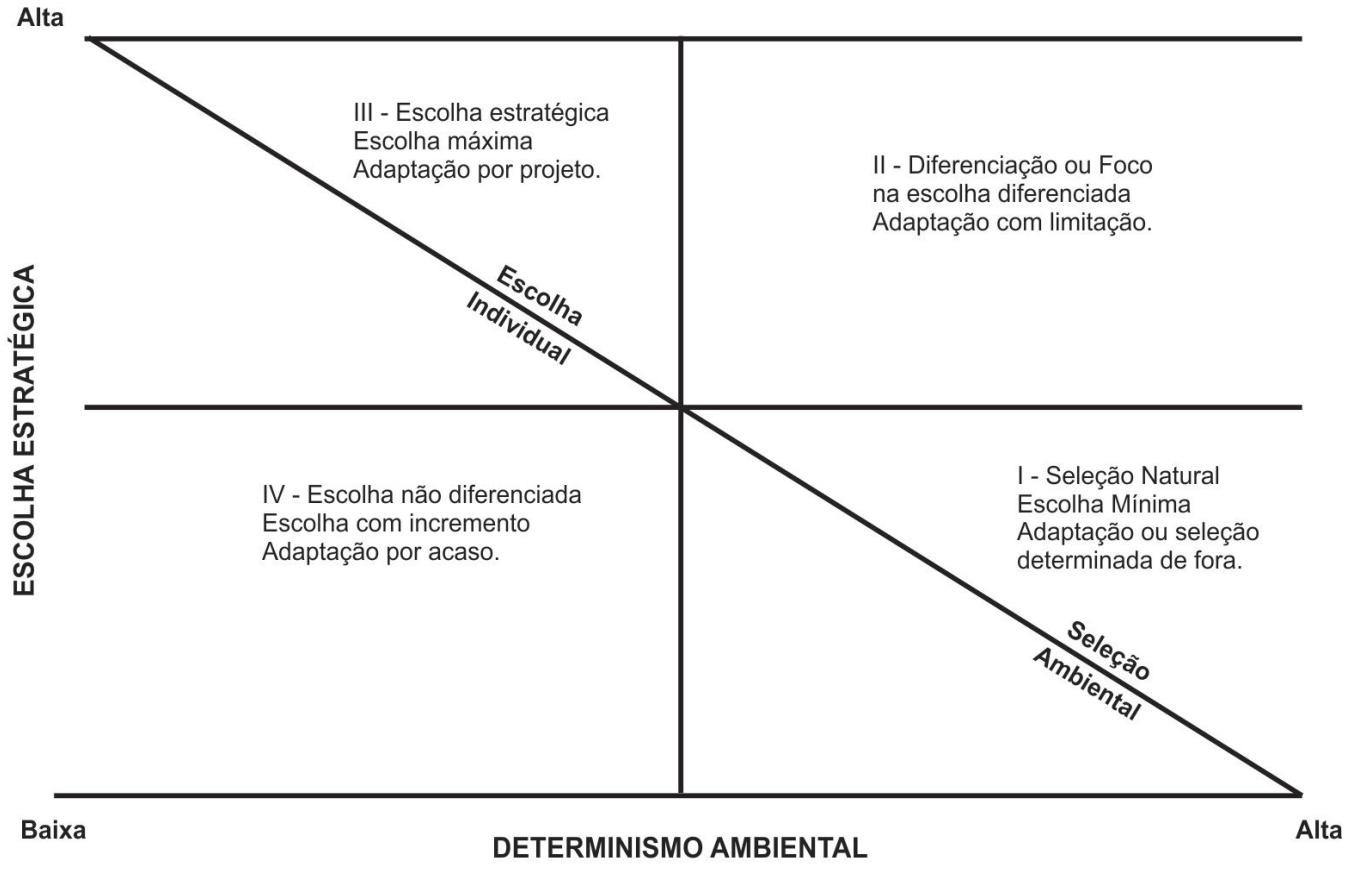

Figura 2. Relação da escolha estratégica e determinismo ambiental na adaptação organizacional Fonte: Adaptado de Hrebiniak e Joyce (1985), pelos Autores (2016).

O quadrante I demonstra as condições de baixa escolha estratégica e alto determinismo ambiental. Nesse quadrante, a adaptação é determinada por fatores externos. $O$ quadrante II é caracterizado pela alta capacidade de escolha estratégica e pelo elevado grau de determinismo, visto que fatores externos podem afetar a tomada de decisão. Já o quadrante III propõe alta escolha organizacional com baixo determinismo ambiental, tendo a autonomia e o controle como regras, onde o ambiente é favorável e os recursos não são escassos, favorecendo a inovação. Por fim o quadrante IV, estabelece uma relação de baixa escolha estratégica e baixo determinismo ambiental. Nesse quadrante, supõe-se uma adaptação por acaso, sem uma estratégia coerente por parte das organizações na busca por vantagem competitiva.

Pereira et. al. (2010) salientam que compete à organização desenvolver as capacidades ou competências necessárias para tomar vantagem em relação às condições ambientais para alterar ou evitar as condições deste quadrante. A análise sugere que o processo de adaptação é dinâmico, e com o passar do tempo à posição da organização pode mudar, como resultado das escolhas estratégicas ou das estratégias em seu ambiente externo.

\section{Visão Baseada em Recursos}

O conceito da Teoria da Visão Baseada em Recursos ou Resource Based View (RBV) foi inicialmente apresentado por Wernerfelf (1984) em um artigo publicado na Strategic Management Journal no ano de 1984. Entretanto, o marco inicial e os propósitos da RBV datam de 1959, baseados em estudos da 
economista Edith Penrose.

Pesquisadores como Barney (1991) e Peteraf (1993), apoiados nos estudos de Penrose (1959), tratam a RBV como uma teoria econômica que sugere que o desempenho das empresas depende dos tipos de recursos e capacidades que elas controlam. De acordo com Barney e Hesterly (2007) recursos devem ser entendidos como ativos tangíveis e intangíveis que uma empresa utiliza para criar e implementar suas estratégias, e capacidades podem ser entendidas como um subgrupo de recursos que permitem que uma empresa tire vantagem de seus outros recursos.

Barney e Hesterly (2007) ressaltam ainda dois pontos importantes. No primeiro, os autores argumentam que empresas diferentes podem possuir conjuntos diferentes de recursos e capacidades, mesmo que estejam competindo em um mesmo setor, ou seja, é a heterogeneidade da imobilidade dos recursos (BARNEY \& HESTERLY, 2007). No segundo, a questão central volta-se para o tempo em que as diferenças existentes entre recursos e capacidades podem ser sustentadas pelas empresas. Isso pode ocorrer, segundo os autores, porque pode ser muito custoso para as empresas, sem certos recursos e capacidades, desenvolvêlos ou adquiri-los (BARNEY \& HESTERLY, 2007).

Wernerfelt (1984) deixa claro que um aumento na lucratividade das empresas pode ser mais bem explicado por seus recursos do que por sua posição de mercado. Nessa mesma ideia, outros estudos surgiram, onde (BARNEY, 1991; PETERAF, 1993) persistem na tentativa de explicar a razão pela qual as empresas têm performances diferentes em um mesmo mercado, já que não há clareza do impacto do ambiente no desempenho delas (BARNEY \& HESTERLY, 2007).

Se, para Porter (1996) as empresas são homogêneas e os recursos são facilmente transferíveis, na RBV, a essência do sucesso está na heterogeneidade, pois os recursos são distribuídos de forma não uniforme na empresa, não sendo transferidos com tanta facilidade (BARNEY, 1991). Nesse sentido, algumas firmas têm um desempenho superior a dos concorrentes, pois elas possuem algo essencial, único e difícil de ser reproduzido pelos rivais (PRAHALAD; HAMEL, 1990; NELSON; WINTER, 1982; BARNEY, 1991).

Os recursos, para a RBV, são entendidos como os ativos, capacidades, processos organizacionais, conhecimento, informação e atributos controlados pela empresa (BARNEY, 1991). Para que sejam considerados fonte de vantagem competitiva, Barney (1991) estabelece quatro atributos que os recursos devem possuir: devem ser valiosos; raros; imperfeitamente imitáveis; e de difícil substituição.

Dierickxx e Cool (1989) destacam que os recursos essenciais para a vantagem competitiva não são, necessariamente, comprados (BARNEY, 2001), mas podem ser acumulados ao longo do tempo pela empresa, com base nas suas escolhas. Tais recursos, em tese, não são transferíveis e não imitáveis, pois não são negociáveis entre empresas (BARNEY, 1991).

Mais recentemente a noção de recurso tem sido ampliada, admitindo-se que seu valor é dependente, pelo menos em parte, de condições ambientais (FOSS; FOSS, 2005). Crubellate et. al. (2008) atribuem essa evolução conceitual dos recursos na RBV à crescente importância de aspectos vinculados à legitimidade da organização, ou seja, um recurso terá valor para a organização se ela tiver reconhecimento pelo seu ajustamento ao ambiente. Assim, a legitimidade pode ser vista de duas maneiras: como um recurso, que pode ser acumulado pela organização ou como a aceitabilidade e reconhecimento que a organização conquista ao assumir pressupostos aceitos pelo ambiente (CRUBELLATE; PASCUCCI; GRAVE, 2008).

Porém, em um mercado de grandes incertezas e competição global, possuir recursos pode não ser suficiente para garantir a sustentabilidade de uma vantagem competitiva. A flexibilidade e a inovação, aliadas à capacidade dos gestores de coordenar e redefinir as competências organizacionais são marcas de empresas vencedoras (TEECE; PISANO; SHUEN, 1997). Nesse pressuposto, a evolução da teoria da RBV demonstra também que, além dos recursos tangíveis e intangíveis, a empresa pode controlar as capacidades dinâmicas e as competências essenciais, tornando-se fonte de Vantagem Competitiva Sustentável.

O conceito de capacidades dinâmicas, conforme Sanchez et. al.(1996) amplia o entendimento da RBV, 
sendo que o termo 'dinâmico', segundo Teece et al(1997), refere-se à capacidade de renovar competências bem como adquirir conformidade com o ambiente de negócios em mudança.

Peteraf (1993) propõe que na busca por recursos e competências que possam gerar vantagem competitiva sustentável, estes devem apresentar as seguintes condições: heterogeneidade, onde os recursos atendem aos preceitos econômicos da escassez, com oferta limitada no mercado; limites à competição ex-ante, relativo à aquisição ou desenvolvimento de recursos que virão a ser raros ou superiores; limites à competição ex-post, onde a empresa deve preservar um recurso valioso, por meio de condições de imperfeita imitabilidade; imperfeita mobilidade, onde o produto possui relação de especificidade com a empresa.

Após uma breve revisão da literatura sobre as teorias mencionadas, percebe-se que o processo de adaptação estratégica de uma organização pode ser analisado segundo as perspectivas de Pettigrew (1987) e Hrebiniak e Joyce (1985) e da Visão Baseada em Recursos. Mesmo considerando diferentes pressupostos teóricos acerca das implicações do ambiente sobre as organizações, ambas as teorias não se apresentam mutuamente excludentes, ao contrário, sua utilização conjunta permite reduzir as limitações individuais de cada teoria e, ainda maximizar 0 entendimento sobre 0 processo de adaptação estratégica das organizações, frente à dinâmica e à natureza multifacetada dos ambientes em que estão inseridas.

\section{Comportamento empreendedor e características empreendedoras}

O termo empreendedor (entrepreneuer) tem origem francesa e significa aquele que assume riscos e começa algo novo e foi utilizado pela primeira vez por Jean Baptist Say, um economista francês, com o objetivo de distinguir o indivíduo que consegue transferir recursos econômicos de um setor com baixa produtividade para um setor com produtividade elevada e com maiores rendimentos. (DRUCKER, 1987). Foi no século XVII que ocorreu a primeira concepção mais clara sobre o termo, onde Schumpeter (1928) sendo um dos colaboradores mais importantes na construção da definição, onde introduziu ao empreendedorismo a palavra inovação. Drucker (1992) analisa o empreendedor como aquele que pratica a inovação sistematicamente, buscando fontes de inovação e criando oportunidades.

O perfil empreendedor é dotado também de outras características. Conforme Dornelas (2008), os empreendedores são visionários, indivíduos que fazem a diferença, sabem explorar as oportunidades, são determinados e dinâmicos, dedicados ao trabalho, otimistas e apaixonados pelo que fazem independentes e construtores do próprio destino, acreditam que o dinheiro é conseqüência do sucesso nos negócios, possuem liderança incomum, sabem construir uma rede de relacionamentos externos à empresa, planejam cada passo do negócio, possuem conhecimento, assumem riscos calculados e criam valor para a sociedade pela qual o empreendimento encontra-se inserido, em busca de soluções para melhorar a vida das pessoas.

Indivíduos que apresentam um forte desejo de independência são mais propensos a explorar oportunidades empreendedoras porque a atividade exige tomada de decisões pessoais ao invés de seguir o julgamento de terceiros (SILVA, et. al., 2013).

Em muitas analises sobre o empreendedorismo é freqüente destacar a oportunidade e a necessidade como razão para empreender, porém o tempo é um fator externo de grande importância para o projeto do empreendedorismo e para que o mesmo ganhe as formas necessárias para o êxito, onde podemos citar: organização, velocidade e maturidade (PEREIRA, 2013).

Para Drucker (1987), o trabalho específico do empreendedor numa empresa de negócios é fazer dos negócios de hoje uma previsão para o futuro, transformando-os em um negócio diferente. Portanto, é possível concluir que a transformação dos negócios de hoje parece depender significativamente da atuação de seus gestores.

Há pesquisas que indicam que empreendedores são pessoas que apresentam um maior desejo de independência, quando comparados ao restante da população, levando-os a tentarem a construir o seu 
próprio negócio. Indivíduos que apresentam um forte desejo de independência são mais propensos a explorar oportunidades empreendedoras porque a atividade exige tomada de decisões pessoais ao invés de seguir o julgamento de terceiros (SILVA, et. al., 2013).

\section{Metodologia}

A pesquisa tratada neste artigo é caracterizada como um estudo de caso exploratório, com abordagem qualitativa. A técnica de coleta de dados utilizada foi à realização de entrevistas semiestruturadas, e para a análise dos dados, empregou-se a técnica de análise de conteúdo. A pesquisa qualitativa, segundo Neves (1996), constitui-se de um conjunto de técnicas de interpretação que buscam a descrição e a decodificação de fenômenos e sistemas em seus diversos componentes. Segundo Godoy (1995), ao implementar uma pesquisa qualitativa, o pesquisador envolve-se diretamente com a situação estudada na busca por dados que descrevam pessoas, lugares e processos e que permitam o entendimento da situação estudada pela visão que têm os sujeitos envolvidos.

A investigação em si foi realizada por meio de um estudo de caso que, segundo Yin (2001), é a metodologia utilizada quando se faz necessário responder a questões do tipo como e por que da ocorrência de certos fenômenos.

O estudo junto à Vinícola se deu por meio de entrevistas estruturadas e questionário, onde esteve representando a vinícola, a Gestora, uma das diretoras da empresa e o enólogo e responsável pela ideia e implantação da produção biodinâmica, os quais estarão aqui denominados como gestores.

Vinícola está localizada no município de Videira, no Estado de Santa Catarina, onde está instalada a planta industrial e parte dos parreirais. A outra parte das videiras está situada no município de Água Doce, também em Santa Catarina, sendo que nesse local iniciou-se a plantação das castas pelo sistema biodinâmico. Formalmente e com foco industrial, as atividades da Vinícola iniciaram no ano de 2006. Antes disso, a produção era feita para consumo próprio, sem comercialização e compartilhado entre amigos. 0 período analisado é de 2005 a 2014, e em cada um deles, buscou-se identificar os fatos mais importantes no processo da mudança.

Utilizou-se nesta pesquisa dados primários, obtidos por meio de duas entrevistas em profundidade, realizadas no período de 25 de Março a 30 de Maio de 2015 com os gestores citados, e dados secundários, como informações sobre estudos científicos já realizados sobre adaptação estratégica e informações gerais sobre o setor produtivo do vinho e o sistema de produção biodinâmico.

Em relação ao tratamento dos dados, foi utilizado o método proposto por Pettigrew (1987) tendo em vista ser uma metodologia amplamente utilizada na literatura e em estudos que tratam de adaptação ou mudança estratégica. Segundo Pettigrew (1987), o ponto de partida da análise de mudança estratégica de uma organização é a noção de que a formulação do conteúdo de uma nova estratégia inevitavelmente implica em gerenciar seu contexto e seu processo. Nesse sentido, o conteúdo refere-se à área específica de transformação sobre investigação. Assim, a empresa buscou adaptar seu processo, tecnologia, produtos, posicionamento geográfico, potencial humano, e até mesmo a cultura organizacional. Quanto ao contexto, 0 autor afirma que se deve analisá-lo interna e externamente, referindo o contexto externo aos ambientes social, econômico, político e competitivo onde a empresa atua e, o contexto interno à estrutura, cultura corporativa e contexto político intrínseco à firma. Enquanto que no processo, a mudança diz respeito às ações, reações e interações das diferentes partes interessadas em mudar o estado atual da firma para um estado futuro.

\section{Apresentação e análise dos dados}

O plantio de uvas e a produção de vinhos no Brasil estão estreitamente ligados à colonização, principalmente a italiana, tendo como porta de entrada o Rio Grande do Sul, onde atualmente a cultura deixou de ser apenas um sustento familiar para se transformar em um negócio (GUERRA et. al., 2009; MELLO, 2009). Com 0 passar do tempo, a viticultura se espalhou pelo país.

A produção brasileira de uvas tem sido superior a um milhão de toneladas. Desse total, 830 mil toneladas 
são usadas para processamento, e o restante consumo in natura e culinária (EMBRAPA UVA E VINHO, 2014). Por outro lado, de acordo com a Uvibra (2013), a produção de vinhos tem superado os 230.000 .000 litros, considerando vinhos de uvas comuns e uvas viníferas.

Segundo o IBRAVIN (2014) do total de produtos industrializados, $77 \%$ são vinho de mesa e $9 \%$ são sucos de uva, ambos elaborados a partir de uvas de origem americana, e cerca de $13 \%$ são vinhos finos, elaborados com castas de vitis vinífera, o restante dos produtos industrializados, $1 \%$ do total, são outros derivados da uva e do vinho. Grande parte da produção brasileira de uvas e derivados é para o comércio interno, o restante é exportado (UVIBRA, 2013). De acordo com a Embrapa Uva e Vinho (2014), as exportações brasileiras do setor vitivinícola ultrapassam os U\$ 155 milhões de dólares, com destaque ao suco de uva, contribuindo com $43 \%$ das vendas ao exterior.

Os quatro estados brasileiros produtores de vinhos finos são: o Rio Grande do Sul (maior produtor), em seguida Santa Catarina e por fim Pernambuco e Bahia (IBGE, 2010). O Estado de Santa Catarina tem sua tradição vitivinícola relacionada com a colonização italiana, sendo as principais regiões produtoras as do Vale do Rio do Peixe, com destaque ao município de Videira (sede da empresa estudada), a Região Carbonífera, no Sul do Estado, e a Região do Vale do Rio Tijucas. Nestas regiões, a viticultura se consolidou com base em cultivares de origem americana, seja para a produção de vinhos de mesa, suco de uva ou uva de mesa (EPAGRI, 2012).

A partir do ano 2000, o propósito do estado é produzir vinhos finos de qualidade. Segundo levantamentos efetuados pela Estação Experimental da EPAGRI/Videira1, a área total de videiras no Estado de Santa Catarina é de 4.070 ha, destes $20 \%$ com variedades de vitis vinífera e $80 \%$ com variedades americanas e híbridas, totalizando entre todas as variedades em torno de $45.709 .640 \mathrm{~kg}$. Conforme a EPAGRI, $70 \%$ da produção destinam-se à produção de vinhos e suco de uva, $5 \%$ à produção de vinho colonial e $25 \%$ ao mercado de uva de mesa.

A vitivinicultura envolve mais de 2.400 famílias e é responsável por cerca de 20.000 empregos diretos no estado de Santa Catarina, inclusive apresenta um aumento médio de 2,33\% na área plantada/ano (IBGE 2010).

Na produção de uvas, os elementos meteorológicos, principalmente, temperatura, umidade e radiação solar, exercem grande influência sobre 0 desenvolvimento, produção e qualidade da uva destinada à elaboração de vinhos (MELLO, 2009). Guerra et. al., (2009), comenta que essa influência ocorre em todos os estágios fenológicos da videira, influenciando a produção de uvas de qualidade.

Além dos elementos meteorológicos, existe um conjunto de fatores que tem total influência na produção de uvas, o qual é chamado de Terroir2, que tem por essência trabalhar simultaneamente fatores do meio natural (clima, solo, relevo) e fatores humanos da produção (variedades, aspectos agronômicos e tecnologia) (TONIETTO, 2007). Vinho de terroir é vinho com todos os requisitos para ser reconhecido como denominações de origem, pois agrega origem, diferenciação e originalidade aos produtos (MELLO, 2009).

\section{0 processo de adaptação estratégica da Vinícola}

A experiência da família proprietária da Vinícola vem de gerações passadas, porém profissionalmente iniciou no ano de 2003. Como já possuíam uma propriedade localizada estrategicamente em uma das principais regiões vinícolas do Estado, no município de Videira, a família teve a iniciativa de plantar uvas acima de 1.000 metros de altitude, com o apoio de um enólogo amigo da família. Esse processo estendeu-se também

\footnotetext{
${ }_{1}^{1}$ EPAGRI - Empresa de Pesquisa Agropecuária e Extensão Rural de Santa Catarina.

${ }^{2}$ A palavra Terroir designa em seu primeiro significado, uma extensão limitada de terra considerada do ponto de vista de suas aptidões agrícolas. Vinhos de Terroir é vinho com todos os requisitos para serem reconhecidos como denominações de origem, pois agregam origem, diferenciação e originalidade dos produtos (MELLO, 2010).
} 
durante 0 ano de 2004.

A primeira vinificação foi para consumo próprio, em 2005, e ocorreu no porão da casa da família, na propriedade em que hoje está situada a vinícola, com a aquisição de alguns tanques de inox e o empréstimo de barricas de carvalho pela Epagri para o envelhecimento do vinho, além de uma engarrafadora, emprestada por uma terceira empresa para o envase. Nesse processo, a família produziu vinhos tintos apenas, dos tipos Cabernet Sauvignon e Merlot, e uma terceira assemblage3, misturando os dois tipos. Nesse período, relacionando ao modelo proposto por Hrebiniak e Joyce (1985) percebe-se uma situação caracterizada por baixa escolha estratégica e baixo determinismo ambiental, onde o produto produzido era sem fins de comercialização e a produção de vinhos ainda não havia se tornado um negócio.

O voluntarismo e a visão por parte "das primas", hoje gestoras e responsáveis pela Vinícola, em possuir um negócio próprio, foi o ponto de partida para profissionalizar a produção. Como o resultado da primeira vinificação foi aceito de maneira positiva por quem consumia, e com o mercado de vinhos em plena ascensão, as futuras gestoras identificaram uma grande oportunidade no setor vinícola.

Mesmo com pouco conhecimento por parte das gestoras, mas com um alto grau de voluntarismo e de baixo determinismo ambiental, em 2006 a vinícola dá sequência no processo de produção, já estruturada como empresa, contando com o auxílio de quatro funcionários que já trabalhavam no vinhedo e a consultoria de dois enólogos, um deles, atual gestor de produção da empresa, e em um ambiente favorável e com abundância de recursos.

Já em 2007, visando diversificar sua capacidade produtiva, a empresa adquiriu novas terras no município de Água Doce, localizado próximo à cidade de Videira, a 1.300 metros de altitude. Nesse mesmo ano, iniciou-se a preparação do solo e o plantio de castas4 tintas dos tipos Cabernet Sauvignon, Merlot, Cabernet Franc, Malbec, Montepulciano e Pinot Noir. Esses fatos demonstram o empreendedorismo e a visão estratégica das gestoras, influenciadas por um alto grau de determinismo e de escolha estratégica, aliados aos recursos disponíveis e ao conhecimento empírico do processo produtivo e do mercado, relacionados ainda com a teoria da Visão Baseada em Recursos, no modelo de Peteraf (1993), ao considerar o terroir adquirido como um recurso raro.

$O$ ano de 2008 marcou definitivamente a inserção da empresa no mercado, com o lançamento dos primeiros vinhos, sendo um tinto e dois brancos. O lançamento ocorreu inicialmente na região onde era produzido, e posteriormente em eventos de degustação na capital do estado, Florianópolis, através do trabalho das próprias gestoras e com o auxílio de uma empresa de assessoria de marketing na etapa inicial. No mesmo ano, a empresa participou da Expo Vinis5em São Paulo.

Novamente influenciadas por elevado grau de determinismo com características voluntaristas, as gestoras perceberam a oportunidade de obter uma condição altamente competitiva através da diversificação do mixe da evolução da roupagem das garrafas, tornando o produto mais nobre e com diferencial estético. Mesmo com traços voluntarísticos, segundo Hrebiniak e Joyce (1985) a adaptação nesse caso é determinada de fora, na medida em que a seleção ocorre pelo próprio ambiente, e a empresa é pressionada a buscar uma vantagem competitiva duradoura.

O ano de 2009 exigiu das gestoras uma alta capacidade de escolha estratégica na tomada de decisão, influenciada por elevado grau de determinismo, já que nesse período a vinícola precisou passar por adequações que demandaram elevados investimentos, para manter-se competitiva no mercado. Essa necessidade da diversificação foi uma resposta à pressão externa, já que devido ao competitivo mercado de importados, a comercialização de vinho nacional para brasileiros torna-se um desafio.

O Brasil oferece um clima muito propício à produção de espumantes, o que permite às vinícolas brasileiras vantagem em relação aos espumantes importados. Percebendo a possibilidade de expansão desse nicho,

\footnotetext{
${ }^{3}$ Mistura de diferentes tipos de uvas no processo de produção de um vinho.

${ }^{4} \mathrm{Na}$ viticultura, representa uma variedade de uvas com características específicas ou semelhantes.

${ }^{5}$ Salão do Vinho das Américas, realizado em São Paulo-SP, e principal evento do segmento.
} 
a empresa optou em fazer uma experiência com esse tipo de produto, e começou a produzir espumantes em uma estrutura terceirizada, investindo apenas no rótulo, oferecendo ao mercado a linha de espumantes. Entendeu-se que obtendo o reconhecimento da qualidade dos espumantes, a qualidade dos vinhos também seria amplamente reconhecida, mesmo entre os importados.

A experiência foi positiva, e ainda em 2009, percebeu-se a possibilidade de expansão desse mercado, impulsionado pelo receio de outras vinícolas em investir nesse tipo de processo, devido ao oneroso investimento. Muitas vinícolas ainda optam pela terceirização da produção de seus espumantes, segundo a gestora da vinícola.

Foi quando a empresa fez a aquisição de seis autoclaves de oito mil litros e a nova linha de envase isobárico para vinhos e espumantes, que exigiu ainda a troca de tubulação para obter uma refrigeração mais potente, sugerindo uma forte relação com a Visão Baseada em Recursos, que possibilitou à empresa responder positivamente a uma oportunidade de mercado, gerando aumento da lucratividade (BARNEY, HESTERLY, 2007), além de manter-se em posição competitiva.

Em 2010, além da instalação da linha de engarrafamento isobárico e das autoclaves para a elaboração dos espumantes charmat6 e da linha de produção dos espumantes de método clássico, houve uma demanda pela diversificação da produção, e a empresa ampliou os vinhedos nas duas propriedades, adquirindo novas mudas e diversificando algumas castas, como a Chardonnay e a Moscato na propriedade de Videira, e as castas Pinot Noir, Chardonnay, Sauvignon Blanc e Prossecco na propriedade de Água Doce, fato que proporcionou aumento da produção e nas vendas, e consequentemente, aumento da lucratividade.

A análise deste fato demonstra mais uma vez a relação com a teoria da Visão Baseada em Recursos, a qual, segundo Barney e Hesterly (2007) proporciona à empresa atender a demanda do ambiente por seu produto, respondendo de modo positivo à questão do valor, proposta pelos autores no modelo VRIO7.

0 ano de 2011 assinala grandes transformações na empresa, reforçando o aspecto de altíssima escolha estratégica aliada à inovação, e o baixo grau de determinismo, com a ocorrência de eventos importantes, como o lançamento do vinho Passito de Moscato Giallo, um vinho fino branco licoroso, com características e sabor singulares, obtidos a partir de um cuidadoso processo produtivo, e com o início da adequação dos vinhedos para o cultivo biodinâmico8, dando início a mais uma etapa de mudança estratégica na empresa.

Com o propósito de produzir vinhos de altíssima qualidade e com a máxima expressão do terroir catarinense, extraindo do solo características verdadeiramente únicas, a Vinícola percebeu na produção biodinâmica uma oportunidade de obter diferencial competitivo através do processo produtivo, colocando-se como uma vinícola com grande diferencial e pioneira no Brasil com esse processo, demonstrando mais uma vez 0 potencial competitivo de suas gestoras, sem necessidade de novos investimentos na estrutura da vinícola.

No ano de 2012, é realizada a colheita das primeiras uvas cultivadas sob o manejo biodinâmico, e o resultado foi uma uva de película mais grossa, resultando em um produto de extrema qualidade, com coloração intensa e riquíssimo aroma, jamais obtidos pelo processo tradicional. Ainda durante esse ano, a Vinícola obteve reconhecimento internacional de seus produtos, ao receber medalha no concurso Decanter World Wine Awards9, em Londres, Inglaterra, com o vinho Moscato Giallo, e em Portugal, no 190 Concours Mondial

\footnotetext{
${ }^{6}$ Processo de fermentação de espumantes mais econômicos que o processo tradicional.

${ }^{7} \mathrm{VRIO}-\mathrm{V}$ de valioso, $\mathrm{R}$ de raro, I de dificilmente imitável e O de Organizável. Modelo proposto por Barney e Hesterly (2007) que integra dois modelos teóricos existentes: a perspectiva de Posicionamento e a Visão Baseada em Recursos.

${ }^{8} \mathrm{O}$ método biodinâmico consiste em entender a propriedade agrícola como uma individualidade, um organismo com seus diferentes componentes: solo, vegetais, animais, recursos naturais e humanos esurgiu a partir de uma série de oito palestras que, em 1924, o filósofo austríaco Rudolf Steiner (18611925) proferiu na Polônia.

${ }^{9}$ Competição mundial de vinhos, fundada em 2004.
} 
de Bruxelles10, um dos mais antigos do mundo no segmento.

Durante a Expo Vinis, em 2013, o primeiro vinho produzido a partir do manejo biodinâmico foi lançado, com o nome iMorTali, obtendo resultado bastante positivo sob o olhar da mídia e dos consumidores, colocando a empresa novamente em um patamar de grande vantagem competitiva, influenciado por altos índices de voluntarismo.

\begin{tabular}{|c|c|c|c|c|}
\hline Ano & Evento & $\begin{array}{l}\text { Adaptação } \\
\text { Organizacional }\end{array}$ & RBV & Características Empreendedoras \\
\hline 2003 & $\begin{array}{l}\text { Plantio das } \\
\text { primeiras } \\
\text { castas }\end{array}$ & $\begin{array}{l}\text { Baixo } \\
\text { determinismo } \\
\text { ambiental }\end{array}$ & & $\begin{array}{l}\text { Sabe explorar as oportunidades; } \\
\text { Determinados e dinâmicos; }\end{array}$ \\
\hline 2005 & $\begin{array}{l}\text { Primeira } \\
\text { vinificação } \\
\text { para consumo } \\
\text { próprio }\end{array}$ & $\begin{array}{l}\text { Baixo } \\
\text { determinismo } \\
\text { ambiental }\end{array}$ & & $\begin{array}{l}\text { Determinados e dinâmicos; Otimistas e } \\
\text { apaixonados pelo que fazem; }\end{array}$ \\
\hline 2006 & $\begin{array}{l}\text { Início do } \\
\text { processo de } \\
\text { profissionaliza } \\
\text { ção }\end{array}$ & Alto voluntarismo & $\begin{array}{l}\text { Valor e } \\
\text { Organizaçã } \\
0\end{array}$ & $\begin{array}{l}\text { Sabe explorar as oportunidades; } \\
\text { Independentes e construtores do } \\
\text { próprio destino; }\end{array}$ \\
\hline 2007 & $\begin{array}{l}\text { Aquisição de } \\
\text { novas terras }\end{array}$ & $\begin{array}{l}\text { Alto determinismo } \\
\text { e alto } \\
\text { voluntarismo }\end{array}$ & $\begin{array}{l}\text { Heterogene } \\
\text { idade }\end{array}$ & $\begin{array}{l}\text { Planeja cada passo do negócio; } \\
\text { Assume riscos calculados; }\end{array}$ \\
\hline 2007 & $\begin{array}{l}\text { Plantio de } \\
\text { novas castas }\end{array}$ & $\begin{array}{l}\text { Alto determinismo } \\
\text { e alto } \\
\text { voluntarismo }\end{array}$ & $\begin{array}{l}\text { Organizaçã } \\
0\end{array}$ & $\begin{array}{l}\text { Planeja cada passo do negócio; } \\
\text { Assume riscos calculados; }\end{array}$ \\
\hline 2008 & $\begin{array}{l}\text { Lançamento } \\
\text { dos primeiros } \\
\text { vinhos }\end{array}$ & Alto voluntarismo & Valor & $\begin{array}{l}\text { Planeja cada passo do negócio; } \\
\text { Assume riscos calculados; }\end{array}$ \\
\hline 2009 & $\begin{array}{l}\text { Início da } \\
\text { produção de } \\
\text { espumantes } \\
\end{array}$ & $\begin{array}{l}\text { Alto determinismo } \\
\text { e alto } \\
\text { voluntarismo }\end{array}$ & $\begin{array}{l}\text { Heterogene } \\
\text { idade }\end{array}$ & Sabe explorar as oportunidades; \\
\hline 2009 & $\begin{array}{l}\text { Aquisição de } \\
\text { novos } \\
\text { equipamentos } \\
\text { para o } \\
\text { engarrafament } \\
\text { o e a } \\
\text { elaboração de } \\
\text { espumantes }\end{array}$ & $\begin{array}{l}\text { Baixo } \\
\text { determinismo e } \\
\text { alto voluntarismo }\end{array}$ & $\begin{array}{l}\text { Limites à } \\
\text { competição } \\
\text { ex-ante }\end{array}$ & $\begin{array}{l}\text { Planeja cada passo do negócio; } \\
\text { Assume riscos calculados; }\end{array}$ \\
\hline 2010 & $\begin{array}{l}\text { Ampliação dos } \\
\text { vinhedos nas } \\
\text { propriedades } \\
\text { de Videira e } \\
\text { Água Doce }\end{array}$ & $\begin{array}{l}\text { Alto determinismo } \\
\text { e alto } \\
\text { voluntarismo }\end{array}$ & $\begin{array}{l}\text { Heterogene } \\
\text { idade }\end{array}$ & $\begin{array}{l}\text { Sabe explorar as oportunidades; } \\
\text { Planeja cada passo do negócio; } \\
\text { Assume riscos calculados; }\end{array}$ \\
\hline 2011 & $\begin{array}{l}\text { Lançamento } \\
\text { do vinho } \\
\text { Passito de } \\
\text { Moscato Giallo }\end{array}$ & Alto voluntarismo & $\begin{array}{l}\text { Imperfeita } \\
\text { mobilidade }\end{array}$ & \\
\hline
\end{tabular}

${ }^{10}$ Considerado um dos mais importantes campeonatos de vinhos do mundo. Fundado em 2007. 


\begin{tabular}{|c|c|c|c|c|}
\hline 2011 & $\begin{array}{l}\text { Início da } \\
\text { adequação } \\
\text { dos vinhedos } \\
\text { para o cultivo } \\
\text { biodinâmico } \\
\text { através de um } \\
\text { profissional da } \\
\text { área }\end{array}$ & $\begin{array}{l}\text { Baixo } \\
\text { determinismo e } \\
\text { alto voluntarismo }\end{array}$ & $\begin{array}{l}\text { Valor e } \\
\text { Organizaçã } \\
0\end{array}$ & $\begin{array}{l}\text { Sabe explorar as oportunidades; } \\
\text { Planeja cada passo do negócio; } \\
\text { Assume riscos calculados; Rede de } \\
\text { relacionamentos externos à empresa; }\end{array}$ \\
\hline 2012 & $\begin{array}{l}\text { Colheita das } \\
\text { primeiras uvas } \\
\text { cultivadas sob } \\
\text { o manejo } \\
\text { biodinâmico }\end{array}$ & $\begin{array}{l}\text { Baixo } \\
\text { determinismo e } \\
\text { alto voluntarismo }\end{array}$ & & $\begin{array}{l}\text { Planeja cada passo do negócio; } \\
\text { Assume riscos calculados; Cria valor } \\
\text { para a sociedade pela qual o } \\
\text { empreendimento encontra-se inserido; }\end{array}$ \\
\hline 2012 & $\begin{array}{l}\text { Obtenção de } \\
\text { reconheciment } \\
\text { o internacional } \\
\text { em concursos }\end{array}$ & Alto determinismo & & $\begin{array}{l}\text { Cria valor para a sociedade pela qual o } \\
\text { empreendimento encontra-se inserido; }\end{array}$ \\
\hline 2013 & $\begin{array}{l}\text { Lançamento } \\
\text { do primeiro } \\
\text { vinho } \\
\text { produzido com } \\
\text { o manejo } \\
\text { biodinâmico }\end{array}$ & Alto voluntarismo & $\begin{array}{l}\text { Limites à } \\
\text { competição } \\
\text { ex-ante }\end{array}$ & $\begin{array}{l}\text { Visionário; Faz a diferença; Sabe } \\
\text { explorar as oportunidades; } \\
\text { Determinado e dinâmico; Dedicado ao } \\
\text { trabalho; }\end{array}$ \\
\hline
\end{tabular}

Quadro 1 - Síntese dos principais eventos do processo de adaptação estratégica da Vinícola.

Fonte: Dados coletados durante a pesquisa. Adaptado pelos autores, 2014.

Após o ano de 2013 (até o momento da realização do estudo) não se observou grandes mudanças ou evoluções. Para os entrevistados, é um período "sabático", para que a empresa possa se organizar em termos de gestão, planejamento e alinhar novos objetivos futuros. Posição que, de alguma forma, configura uma característica empreendedora e proativa, logo demonstrando voluntarismo.

\section{Limitações do estudo}

Durante a realização do estudo, algumas limitações foram observadas: (1) O Brasil não possui um banco de dados oficial e completo sobre a produção vitivinícola, muito menos algo registrado em relação ao uso da produção biodinâmica na produção de vinhos; (2) Em buscas junto a órgãos do setor (EMBRAPA Uva e Vinho e Ibravin) tudo indica que, profissionalmente, a VSA é a primeira vinícola a produzir vinhos oriundos de produção biodinâmica; (3) Os gestores da Vinícola não souberam precisar números, principalmente em termos de custos, mas estão na construção dos mesmos - plantação, produção e transformação - para, em breve, formar o preço real para comercialização. De qualquer forma, acredita-se que tais limitações não interferem no resultado final ao qual esse artigo se propôs.

\section{Considerações finais}

Este artigo teve como objetivo identificar a influência do comportamento empreendedor das gestoras no processo de adaptação estratégica da Vinícola, tomando como base o modelo proposto por Pettigrew (1987) e as influências do determinismo ambiental e do voluntarismo, sob o modelo de Hrebiniak e Joyce (1985) e da perspectiva da Visão Baseada em Recursos.

Mediante as informações colhidas junto aos responsáveis pela Vinícola, e comparando com as teorias apresentadas neste artigo, ficou evidente que a mudança organizacional tem contribuído para que as 
empresas tenham perenidade em mercados cada vez mais competitivos, obtendo diferenciais de sucesso e contribuindo para o desenvolvimento do seu setor de atuação.

As estratégias de adaptação da empresa ao longo do seu processo, os recursos disponíveis em cada período e o perfil empreendedor de suas gestoras, aliado ao elevado grau de voluntarismo que influenciou todo o processo de profissionalização e constante inovação da empresa, tiveram como resultado uma posição de mercado altamente competitiva, um produto diferenciado e de alto valor agregado, oriundo da aplicação de uma tecnologia relativamente nova, principalmente no ramo da viticultura, que é a produção através do processo biodinâmico, fato que demonstra maturidade e visão estratégica, em uma empresa relativamente jovem e em um setor de complexa atuação.

Em momento algum do processo de adaptação da Vinícola, evidencia-se ausência de relação com o modelo de Hrebiniak e Joyce (1985) ou da Visão Baseada em Recursos, com total ausência de inércia organizacional por parte da empresa, o que reflete características de empreendedorismo aliados à visão de oportunidades e constante busca pela inovação. Destaca-se ainda a questão de correr riscos, aceitá-los e transpô-los, ponto esse ingrediente do perfil empreendedor, e identificado em toda a trajetória da empresa e de suas gestoras.

\section{Referências}

ANSOFF, H. I. Corporate strategy: an analytic approach to business policy for growth and expansion. New York: McGraw-Hill, 1965.

ASTLEY; W.G.; VAN DE VEN; A.H. Central perspectives and debates in organization theory. Administrative Science Quarterly, 28:245-273, 1983.

BARNEY, J. B. Firm Resources and Sustained Competitive Advantage. Journal of Management, v. 17, n. 1, 99-120, 1991.

BARNEY, J. B. Is the resource-based "view" a useful perspective for strategic management research? Yes. Academy of Management Review, v. 26, 2001.

BARNEY, Jay.; HESTERLY, W.S. Administração Estratégica e Vantagem Competitiva. São Paulo: Pearson Prentice Hall, 2007.

CARVALHO, C. E.; ROSSETTO, C. R.; VIANNA, S. L. G. Determinismo e voluntarismo na adaptação estratégica: o caso de uma empresa de varejo. Base. v. 8, n. 4, p. 286 $-299,2011$.

CRUBELLATE, J. M.; PASCUCCI, L.; GRAVE, P. S. Contribuições para uma visão baseada em recursos legítimos. Revista de Administração de Empresas, v. 48, n. 4, 2008.

DIERICKXX, I.; Cool, K. Asset stock accumulation and sustainability of competitive advantage.Management Science. v. 35, n. 12, dez. 1989.

DORNELAS, J. C. A. Empreendedorismo Corporativo: como ser empreendedor, inovar e se diferenciar na sua empresa. Rio de Janeiro: Elsevier, 2003.

DORNELAS, J. C. A. Empreendedorismo: transformando idéias em negócios. 3. ed., rev. e

DRUCKER, Peter F. (1987) - Inovação e Espírito Empreendedor- Entrepreneuship. São Paulo: Editora Pioneira.

DRUKER, P. F. Administrando para o futuro: os anos 90 e a virada do século.São Paulo: Ed. Pioneira.

EMBRAPA, Uva e Vinho. Conhecendo o essencial sobre uvas e vinhos / Celito ISSN 2318-9231

CGE * v . ${ }^{*}$ n. 2 * Mai-Ago 2017 * 01-17 
Crivellaro Guerra...[et al.]. - Bento Gonçalves: Embrapa Uva e Vinho, 2014. 69 p.:il.; 10 cm. -- (Documentos / Embrapa Uva e Vinho, ISSN 1516-8107; 48). 1. Viticultura. 2. Uva. 3. Variedade. 4. Enologia. 5. Vinho. 6. Classificação. 7. Análise Sensorial. 8. Espumante. I. Guerra, Celito Crivellaro. II. Mandelli, Francisco. III. Tonietto, Jorge. IV. Zanus, Mauro Celso. V. Camargo, Umberto Almeida. VI. Série.

FOSS, K; FOSS, N. Resources and transaction costs: how property rights economics furthers the resource-based view. Strategic Management Journal, v. 26, n. 6, 2005.

GODOY, Arilda Schmidt. Pesquisa qualitativa: tipos fundamentais. Revista de administração de empresas - RAE, São Paulo, v.35, n.3, p.20 a 25, maio/jun., 1995a.

GUERRA, Celito Crivellaro et. al. Conhecendo o essencial sobre uvas e vinhos. Bento Gonçalves: Embrapa Uva e Vinho, 2009. 69 p.:il.; 10 cm. - (Documentos / Embrapa Uva e Vinho, ISSN 1516-8107; 48). 1. Viticultura. 2. Uva. 3. Variedade. 4. Enologia. 5. Vinho. 6. Classificação. 7. Análise Sensorial. 8. Espumante. I. Guerra, Celito Crivellaro. II. Mandelli, Francisco. III. Tonietto, Jorge. IV. Zanus, Mauro Celso. V. Camargo, Umberto Almeida. VI. Série. $\quad$ Disponível em www.cnpuv.embrapa.br/publica/documentos/doc048.pdf.

HAMEL, Gary; PRAHALAD, C. K. Competindo pelo futuro: estratégias inovadoras para obter o controle do seu setor e criar os mercados de amanhã. Rio de Janeiro: Campus, 1995.

HISRICH, R.; PETERS, M. Empreendedorismo. Porto Alegre: Bookman, 2004.

HREBINIAK, Lawrence G.; JOYCE, Willian. Organizational adaptation: strategic choice and environmental determinism.Administrative Science Quarterly, USA, v.30, n3, p. 336-349, Sept., 1985.

IBGE - Instituto Brasileiro de Geografia e Estatística - Cidades, 2010. Disponível em http://www.ibge.gov.br/cidadesat/topwindow.htm?1. Acessado dia 12/ 04/ 2016.

IBRAVIN - Instituto Brasileiro do Vinho. Comercialização de vinhos - Empresas do Rio Grande do Sul, Brasil - comparação 2004-2009. Disponível em http://www.ibravin.org.br/admin/UPLarquivos/200420101624142.pdf. Acessado dia 12/ 04/ 2016.

2004-2010.

Importações brasileiras de vinhos e espumantes: comparativo http://www.ibravin.org.br/admin/UPLarquivos/220220111854462.pdf. Acessado dia 20/ 04/ 2016.

MELLO, Loiva Maria Ribeiro. Viticultura brasileira: panorama 2011. Embrapa Uva e Vinho; Produção Técnica. Bento Gonçalves, 2009.

MILES, R. E.; SNOW, C. C. Organizational strategy, structure, and process. New York: McGraw-Hill, 1978.

MINTZBERG, HENRY; QUINN, James B. O processo da Estratégia. Porto Alegre: Bookman, 2001.

MOTTA, Paulo Roberto. Transformação organizacional. Rio de Janeiro: Qualitymark, 2001.

NELSON, R.; WINTER, S. G. An evolutionary theory of economic change. 
Cambridge: Harvard University Press, 1982.

NETO, A. R.; FREITAS, L. S. Análise do processo de adaptação estratégica de uma empresa produtora de cachaça à luz da Teoria Institucional e da Visão Baseada em Recursos. Revista Eletrônica de Administração. V.71, n. 1, p. 211 - 241, 2012.

NEVES, JOSÉ LUIS. Pesquisa qualitativa - Características, usos e possibilidades. Caderno de Pesquisa em Administração, São Paulo, V. 1, n 3, 2 sem. 1996.

PENROSE, E. The Theory of the Growth of the Firm. New York: Oxford University Press, 1959.

PEREIRA, G. D. F.; CORDEIRO, A. T.; DA SILVA, M. A. P.; BATISTA, M. de M. Empreendedorismo regional: um olhar sobre a identidade cultural em narrativas locais. R. Negócios, Blumenau, v.18, n.2, p. 3-26, abr./jun. 2013.

PEREIRA, G. D. F.; CORDEIRO, A. T.; DA SILVA, M. A. P.; BATISTA, M. de M. Empreendedorismo regional: um olhar sobre a identidade cultural em narrativas locais. R. Negócios, Blumenau, v.18, n.2, p. 3-26, abr./jun. 2013.

PEREIRA, M. F.; RIBEIRO, M. L. G.; LISONI, J.; CARIO, S. F. Processo de mudança e adaptação estratégica em uma empresa familiar brasileira: o caso da Reunidas S/A. Revista Organizações em contexto, Ano 6, n. 11, p. 86-124, 2010.

PETERAF, M. The cornerstones of competitive advantage: a resource-based view. Strategic Management Journal. v. 14, 1993.

PETTIGREW, ANDREW. M. Context and action in the transformation of the firm. Journal of Management Studies, v. 24, n. 6, 1987.

PORTER, Michael E. Vantagem competitiva: criando e sustentando um desempenho superior. Rio de Janeiro: Campus, 1989.

PRAHALAD, C. K.; HAMEL, Gary. The core competence of the corporation. Harvard Business Review, v. 68, May/Jun. 1990.

ROSSETO, Carlos Ricardo; ROSSETTO, Adriana Marques. Teoria Institucional e dependência de recursos na adaptação organizacional: uma visão complementar. RAE eletrônica, Fundação Getúlio Vargas - Escola de administração de Empresas de São Paulo, São Paulo, v.4, n.1, art.7, jan. a jun., 2005.

SANCHEZ, R.; HEENE, A.; THOMAS, $H$. Dynamics of competence-based competition: theory and practice in the new strategic management.Oxford: Pergamon, 1996.

SILVA, T.; PEREIRA, M. F.; COSTA, A. M.; HINTERLANG, C. Metodologia em voga no campo de empreendedorismo: emprego de métodos quantitativos para o estudo das características inerentes ao empreendedorismo. RIAE, São Paulo, v. 12 n. 4, p. 181-208, out./dez. 2013.

SILVA, T.; PEREIRA, M. F.; COSTA, A. M.; HINTERLANG, C. Metodologia em voga no campo de empreendedorismo: emprego de métodos quantitativos para o estudo das características inerentes ao empreendedorismo. RIAE, São Paulo, v. 12 n. 4, p. 181-208, out./dez. 2013.

TEECE, D. J.; PISANO G. SHUEN, A. Dynamic Capabilities and Strategic Management. Strategic Management Journal, vol.18:71997.

TONIETTO, J. Afinal, o que é Terroir? Bon Vivant, Flores da Cunha, v. 8, n. 98, p. 08, abr.

2007.

Disponível

em: 
http://www.cnpuv.embrapa.br/download.php?file=publica/artigos/afinal_o_que_terroir.pd f>. Acessado dia 16/ 05/ 2016.

UVIBRA - União Brasileira de Vitivinicultura. Produção de uvas, elaboração de vinhos e derivados: 1998 - 2010, 2010. Disponível em: http://www.uvibra.com.br/pdf/safra_uva1998-2010.pdf. Acessado dia 20/ 05/ 2016.

VASCONCELOS, F.; CYRINO, A. Vantagem competitiva: os modelos teóricos atuais e a convergência entre estratégia e teoria organizacional. Revista de Administração de Empresas, v. 40, n. 4, 2000.

VEGINI, G.; LEITE, A. L.; FIATES. G. Desempenho competitivo da WEG: uma análise à luz da adaptação estratégica. Revista Contemporânea de Economia e Gestão, v. 9, n. 2, Jul./Dez. 2011.

WERNERFELT, B. A resource-based view of the firm. Strategic Management Journal, v. 5, n. 2, Apr.-June. 1984.

YIN, R. K. Estudo de caso: planejamento e métodos. Porto Alegre, Bookman, 2001. 